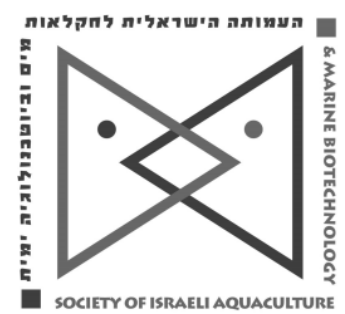

The IJA appears exclusively as a peer-reviewed on-line open-access journal at http://www.siamb.org.il. To read papers free of charge, please register online at registration form.

\title{
Histopathological Changes in Gills, Liver, and Kidney Tissues of Bighead Carp (Aristichthys nobilis) Due to the Effects of Acute High-Temperature Stress
}

\author{
Emmanuel Rufino Aboka* 1, 2 , Zhu Jian 1, 2, *, Sun Shengming ${ }^{2}$, \\ Zhang Wuxiao ${ }^{1}$, Yu Han ${ }^{1}$, Su Yan Li ${ }^{1}$, Yu Jiahui ${ }^{1}$, Zhu Jiabin ${ }^{1}$ \\ ${ }^{1}$ Wuxi Fisheries College, Nanjing Agricultural University, Wuxi, \\ Jiangsu 214081, China \\ ${ }^{2}$ Key Laboratory of Freshwater Fisheries and Germplasm Resources \\ Utilization, Ministry of Agriculture, Freshwater Fisheries Research \\ Centre, Chinese Academy of Fishery Sciences, Wuxi, Jiangsu \\ 214081, China
}

Keywords: Bighead carp Aristichthys nobilis; temperature; stress; histopathological change

\begin{abstract}
Histopathological evaluation of fish tissues is a reliable method for detecting exposure to toxins and other environmental problems that cause stress or even death. This study aimed to evaluate histopathological changes that occur in internal organs of Bighead carp (Aristichthys nobilis) following acute high-temperature stress. By examining tissues sampled at various times after heat shock $(3,6,12$, and 24 hours), we observed considerable anatomical changes in three vital organs. In the gills, epithelial lifting and edema, blood congestion, primary lamellae thickening, and secondary lamellae curling, shortening, and fusion were evident; in the liver, karyolysis, necrosis, hyperemia, dilation of sinusoids, nuclear hypertrophy, and congestion of the central vein were observed; the kidneys displayed dilation of the Bowman's space, an increase in the diameter of the renal tubules, hyperemia, shrinkage and congestion of the glomeruli, and tubular necrosis. This analysis indicates that Bighead carp are highly susceptible to changes in environmental temperature, and rapid intervention is required in response to temperature fluctuations in aquaculture. This study should encourage aquaculturists to monitor culture temperatures for this economically important species of fish.
\end{abstract}

*Correspondence author: Zhu Jian; Tel.:+8613861700506; E-mail: zhuj@ffrc.cn E.R. Aboka; Tel.: +211955718383; E-mail: emmanuelrufinson@yahoo.com 


\section{Introduction}

Fish are cold-blooded aquatic vertebrates. Temperature is an important environmental factor in aquaculture that affects survival and growth. Fish are highly susceptible to seasonal and diurnal variations in water temperature. Any fluctuations in temperature may influence fish survival, alter physiology, and disrupt biochemical pathways and enzymatic activities (Lee et al., 2014). When the environmental temperature reaches the upper limits of tolerance, it can induce stress responses in fish. Depending on the intensity and duration of these fluctuations, thermal stress is considered either acute or chronic. In nature, most thermal stress is acute because it normally involves a significant temperature change over a short time period of time.

Histology is a sensitive tool for examining the effects of toxicity in animal tissues (Paithane et al., 2012). Histology can detect signs of disease not easily recognized by gross physical examination, and can therefore be useful in assessing animal health. In aquaculture, fish are excellent bioindicators of environmental pollution because their tissues absorb toxins from the water they inhabit and from contaminated organisms that they eat (Fisk et al., 2001). Due to their frequent exposure to pollutants and the subsequent physiological stress they undergo, major structural damage and histological abnormalities are often observed in their internal organs. This stress typically disrupts organ physiology and metabolic processes. Thus, histology is an effective means of evaluating the health of fish exposed to contaminants and, more broadly, in assessing the extent of pollution in the trophic web (Thophon et al., 2003; Marina et al., 2007).

Bighead carp is one of the most economically important freshwater filter-feeding fish in Asia and constitutes the majority of carp aquaculture production in China, yielding an annual production of 3.25 million tons in 2014 (FAO, Fish stat, 2014). Bighead carp can tolerate extreme changes in water temperature ranging from those normally found in cold, temperate, and tropical climates. The maximum temperature at which Bighead carp can survive is $38^{\circ} \mathrm{C}$ (USGS, 2005) and lowest temperature they can tolerate is close to freezing at $1^{\circ} \mathrm{C}$ (ISSG, 2005). The preferred temperature for optimal reproduction is about $25^{\circ} \mathrm{C}$ (USGS, 2005). Bighead carp feeds on both phytoplankton and zooplankton, with phytoplankton constituting a substantial part of their diet (Opuszynski, 1981). Because of their filter-feeding habits, Bighead can be used to control algal blooms (Cremer and Smitherman, 1980). As such, it is a highly desirable aquacultural species, and is now widely exported from China to more than 70 other countries.

In the present study we investigated histopathological changes in the gills, liver, and kidneys of the Bighead carp ( $A$. nobilis) following acute high-temperature stress.

\section{Materials and Methods}

Experimental layout. Healthy Bighead carp (A. nobilis) were obtained from Nanquan fish farm, which is part of the Freshwater Fisheries Research Center, Chinese Academy of Fishery Science in Wuxi, China. Experiments were carried out in a closed freshwater recirculating system with a water flow rate of about $3 \mathrm{~L} / \mathrm{min}$ and continuous aeration. 54 fish were acclimatized in $300 \mathrm{~L}$ dechlorinated freshwater tanks for two weeks, and fed to near satiation three times daily with a commercial diet. Following this adaptation period, fish with a mean weight of $250 \pm 66 \mathrm{~g}$ were selected and randomly distributed into two treatment groups (control and heat stress; with three tanks (replications) of each treatment, with 9 fish per tank. Uneaten feed and feces were siphoned out on a daily basis. During the experiment the water parameters were: temperature, $28^{\circ} \mathrm{C}$, dissolved oxygen concentration, $>6.0 \mathrm{mg} / \mathrm{L}$, total ammonia-nitrogen concentration, $<0.05 \mathrm{mg} / \mathrm{L}, \mathrm{pH}, 7.0-7.5$. These conditions were monitored weekly. Photoperiod was $12 \mathrm{hr}$ light/12 hr dark. All husbandry procedures and experiments were carried out in accordance with local and international animal welfare policies stipulated by scientific research protocols (CAFS) and the Ministry of Agriculture, PR China (FAO, 2004).

Temperature Stress experiments. Prior to the temperature stress experiment, fish were reared at $28^{\circ} \mathrm{C}$ for 10 weeks. The first sample was collected after $24 \mathrm{hr}$. Thereafter a subsample of 36 fish from the two groups were exposed gradually 


\section{Histopathological changes in tissues of bighead carp following acute \\ high-temperature}

every $3 \mathrm{~h}$ to $38^{\circ} \mathrm{C}$ for $24 \mathrm{hr}$ and samples were collected at each step. A $12 / 12 \mathrm{~h}$ light/dark, as well as $\mathrm{pH}, 7.0-7.5$, ammonia-nitrogen concentration, $<0.05 \mathrm{mg} / \mathrm{L}$, dissolved oxygen, $>6.0 \mathrm{mg} / \mathrm{L}$ were constant during the duration of the experiment. Human interference was minimized to prevent additional stress to the fish.

Histopathological observations. Tissue samples were taken from fish collected with a net from each tank $24 \mathrm{hr}$ after the last feeding, ensuring that the animals had evacuated gut contents. Samples of three fish were then anesthetized with MS-222 (Tricaine methanesulfonate, Sigma, (USA) at a concentration of $100 \mathrm{mg} / \mathrm{L}$. Samples were taken once before the temperature challenge $(0 \mathrm{hr})$ and then at $3,6,12$, and $24 \mathrm{hr}$. The gills, liver, and kidneys were prepared for histological analysis according to standard procedures: fixed in Bouin's fixative for $24 \mathrm{hr}$ to avoid post-mortem changes and shrinkage. The fixed tissues were then dehydrated in a graded ethanol series, cleaned in xylene, and embedded in paraffin wax. Sections $(4 \mu \mathrm{m})$ were stained with hematoxylin and eosin (H\&E). The following symbols were used to denote the degree and extent of structural changes in the tissues: no alteration $(-)$, mild $(+)$, moderate $(++)$, and severe $(+++)$. The stained sections were examined under a light microscope and photographed with a mounted digital camera.

\section{Results}

Effects of acute high-temperature stress on the gill tissues. Gill tissues were examined histologically after exposure to acute high-temperature stress and compared to the control (Table 1, Fig. 1). In the control, gills displayed double rows of filaments or primary lamellae perpendicularly oriented to the secondary lamellae. The primary gill lamellae was lined by a thick stratified epithelium, which is known to contain numerous mucous-secreting cells and chloride-enriched cells that are found between the secondary lamellae. The secondary gill lamellae were found to be highly vascularised and surrounded by a thin layer of epithelial cells.

Table. 1 Summarized histopathological alteration in the gill of Bighead carp Aristichthys nobilis exposed to acute high temperature stress for $24 \mathrm{hr}$.

\begin{tabular}{lccccc}
\hline Tissue and histopathology & Control & $\mathbf{3 h}$ & $\mathbf{6 h}$ & $\mathbf{1 2 h}$ & $\mathbf{2 4 h}$ \\
\hline Epithelial lifting & - & + & - & - & ++ \\
Edema epithelium & - & + & - & - & ++ \\
Blood congestion & - & + & ++ & +++ & - \\
Curling of secondary lamellae & - & - & ++ & +++ & - \\
Thickening of primary lamellae & - & - & - & - & ++ \\
Fusion on the secondary lamellae & - & - & - & ++ & ++ \\
Shortening of secondary lamellae & - & - & - & - & +++ \\
\hline
\end{tabular}

Note none: $(-)$, mild: $(+)$, moderate: $(++)$ and severe: $(+++)$ 

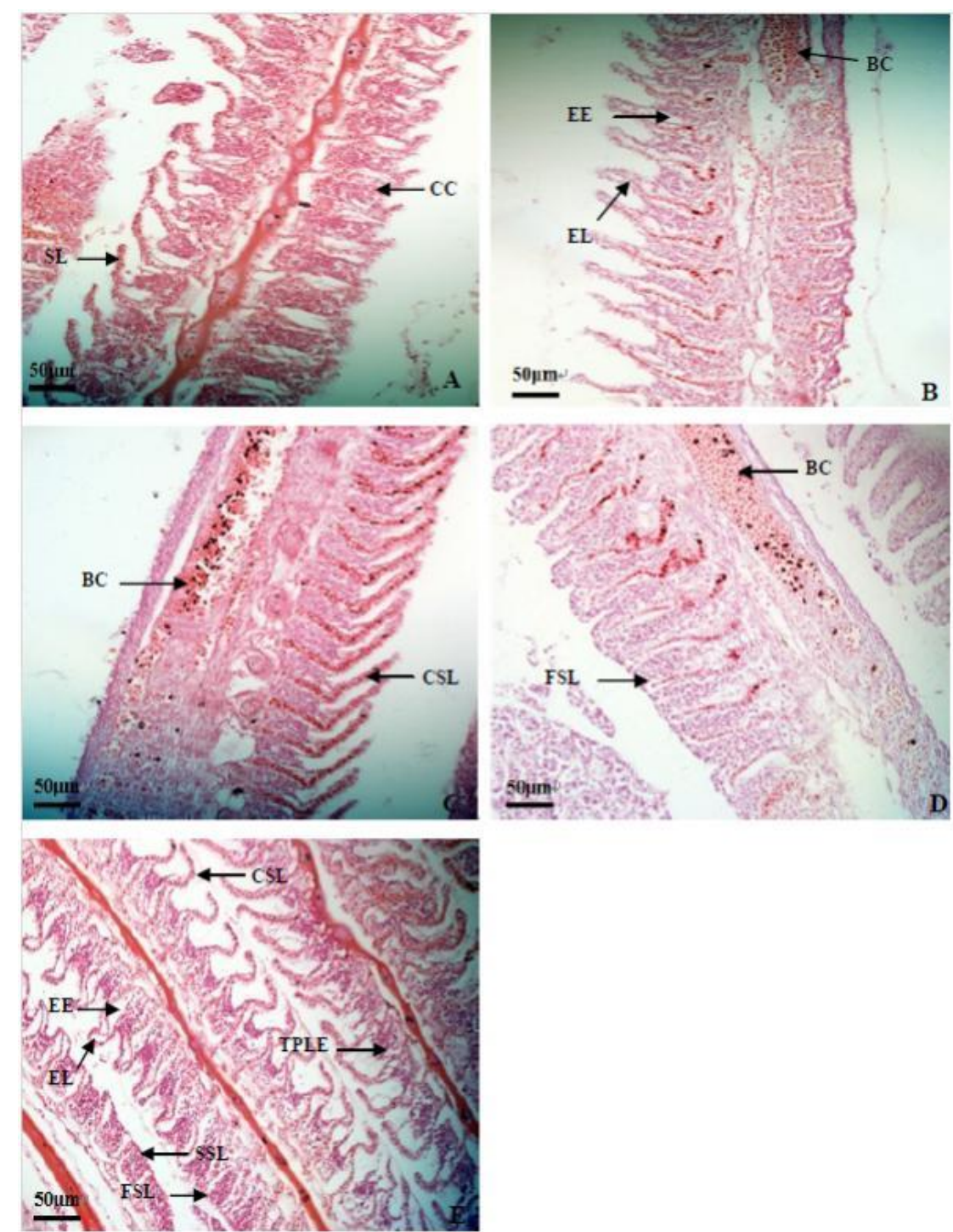

Fig. 1 (A-E) Histopathological evaluation of Aristichthys nobilis gill tissues exposed to acute high-temperature stress. (A) Gills of control fish at $28^{\circ} \mathrm{C} ; 200 \times$. (B) Gills after $3 \mathrm{hr}$ at $38^{\circ} \mathrm{C} ; 200 \times$. (C) Gills after $6 \mathrm{hr}$ at $38^{\circ} \mathrm{C} ; 200 \times$. (D) Gills after $12 \mathrm{hr}$ at $38^{\circ} \mathrm{C} ; 200 \times$. (E) Gills after $24 \mathrm{hr}$ at $38^{\circ} \mathrm{C} ; 200 \times$. Epithelial lifting, EL; secondary lamellae, SL; edema of epithelium, EE; blood congestion, $\mathrm{BC}$; chloride cell, CC; curling of secondary lamellae, CSL; fusion of the secondary lamella, FSL; thickening of primary lamellae epithelium, TPLE; shortening of secondary lamellae, SSL. All sections stained with H\&E. Scale bar (50) $\mu \mathrm{m}$.

Respiratory epithelial cells and pillar cells were situated between blood capillaries, and chloride cells were located at the base of two adjacent lamellae (Fig. 1A). In contrast, disrupted gill morphology was observed after only $3 \mathrm{hr}$ of acute high-temperature stress. Epithelial lifting, blood congestion, and edema of the gill epithelium was observed (Fig.1B). Curling of secondary lamellae and blood congestion was later observed after $6 \mathrm{hr}$ of temperature stress (Fig. 1C). At $12 \mathrm{hr}$, blood congestion and fusion of the secondary lamellae occurred (Fig. 1D). Finally, these changes worsened by $24 \mathrm{hr}$ of heat shock. The secondary lamellae displayed extensive curling and fusion. In addition, lifting and edema of the epithelium was observed, coupled with thickening and shortening of the primary lamellae (Fig. 1E).

Effects of acute high-temperature stress on the liver tissues. Liver tissues were examined histologically after exposure to acute high-temperature stress and compared to control livers (Table 2, Fig. 2). 


\section{Histopathological changes in tissues of bighead carp following acute high-temperature}

Table. 2 Summarized histopathological alteration in the liver of Bighead carp Aristichthys nobilis exposed to acute high temperature stress for $24 \mathrm{hr}$

\begin{tabular}{lccccc} 
Tissue and histopathology & Control & $\mathbf{3 h}$ & $\mathbf{6 h}$ & $\mathbf{1 2 h}$ & $\mathbf{2 4 h}$ \\
\hline Karyolysis & - & + & - & - & - \\
Necrosis & - & + & ++ & +++ & - \\
Hyperemia & - & - & ++ & ++ & + \\
Dilation in sinusoids & - & - & + & + & +++ \\
Nuclear hypertrophy & - & - & + & ++ & ++ \\
Congestion of central vein & - & - & - & ++ & - \\
\hline
\end{tabular}

Note none: $(-)$, mild: $(+)$, moderate: $(++)$ and severe: $(+++)$

In the control, hepatocytes were located among blood capillaries called sinusoids. These hepatocytes formed cord-like structures known as hepatic cell cords. The sinusoid lumens contained mainly erythrocytes caused by venous blood enters the liver caudally from the intestine via the hepatic portal veins, and branches into the sinusoids. As a result, these sinusoids were found to be lined with reticuloendothelial cells surrounded by more hepatocytes (Fig. 2A). In contrast, after $3 \mathrm{hr}$ of heat stress, livers displayed karyolysis (Fig. 2B). After $6 \mathrm{hr}$, livers had dilated sinusoids, necrosis, nuclear hypertrophy, and hyperemia (Fig. 2C). The severity of these histological alterations increased after $12 \mathrm{hr}$ of heat shock, causing hyperemia, central vein damage, necrosis, nuclear hypertrophy, and dilatation of the sinusoids (Fig. 2D). Finally, by $24 \mathrm{hr}$, nuclear hypertrophy, sinusoid dilatation, and hyperemia were especially evident (Fig. 2E).
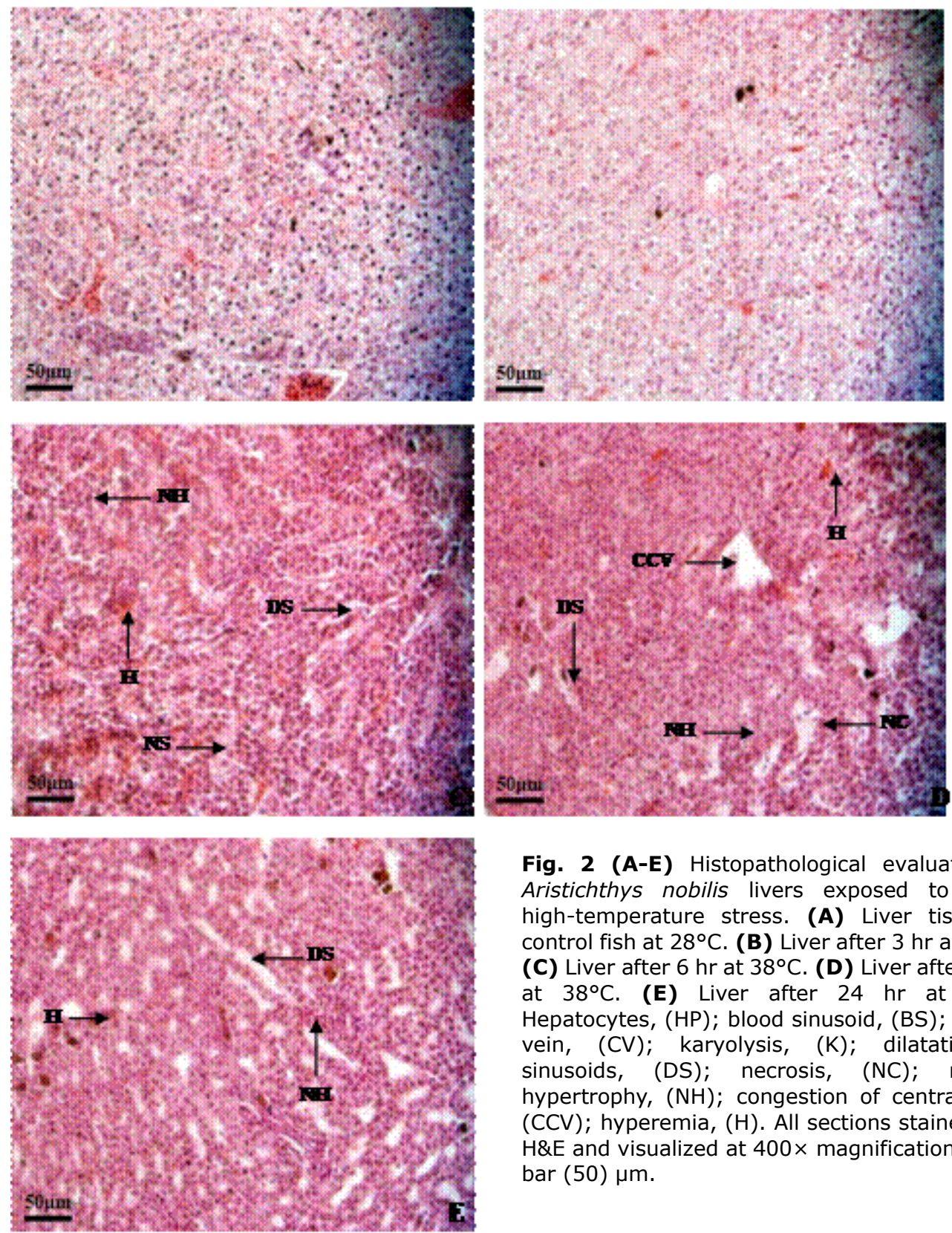

Fig. 2 (A-E) Histopathological evaluation of Aristichthys nobilis livers exposed to acute high-temperature stress. (A) Liver tissue of control fish at $28^{\circ} \mathrm{C}$. (B) Liver after $3 \mathrm{hr}$ at $38^{\circ} \mathrm{C}$. (C) Liver after $6 \mathrm{hr}$ at $38^{\circ} \mathrm{C}$. (D) Liver after $12 \mathrm{hr}$ at $38^{\circ} \mathrm{C}$. (E) Liver after $24 \mathrm{hr}$ at $38^{\circ} \mathrm{C}$. Hepatocytes, (HP); blood sinusoid, (BS); central vein, (CV); karyolysis, (K); dilatation of sinusoids, (DS); necrosis, (NC); nuclear hypertrophy, $(\mathrm{NH})$; congestion of central vein, (CCV); hyperemia, $(\mathrm{H})$. All sections stained with $\mathrm{H} \& \mathrm{E}$ and visualized at $400 \times$ magnification. Scale bar (50) $\mu \mathrm{m}$. 
Effects of acute high-temperature stress on the kidneys tissues. Kidney tissues were examined histologically after exposure to acute high-temperature stress and compared to control kidneys (Table 3, Fig. 3). In controls, the functional units of the kidney (nephrons) were composed of well-organized renal corpuscles and renal tubules. These structures were surrounded by haemopoietic tissues. As expected, the renal corpuscles were roughly spherical in shape, consisting of a double membrane capsule (Bowman's capsule) enclosing a tuft of blood capillaries (glomerulus) (Fig. 3A). In contrast, after $3 \mathrm{hr}$ of acute high-temperature stress, the kidneys displayed a dilation of the Bowman's space and an increase in the diameter of the renal tubules (Fig. 3B). Moreover, hyperemia, shrinkage of glomerulus, and renal tubule necrosis were observed after $6 \mathrm{hr}$ of heat shock (Fig. 3C). After $12 \mathrm{hr}$, Bowman's space dilated significantly. Hyperemia, tubular necrosis, and glomerular congestion were also observed (Fig. 3D). The severity of these alterations increased after $24 \mathrm{hr}$ of heat shock, resulting in extensive glomerular congestion, hyperemia, and tubular necrosis (Fig. 3E).

Table. 3 Summarized histopathological alteration in the kidney of Bighead carp Aristichthys nobilis exposed to acute high temperature stress for $24 \mathrm{hr}$.

\begin{tabular}{lccccc}
\hline Tissue and histopathology & Control & $\mathbf{3 h}$ & $\mathbf{6 h}$ & $\mathbf{1 2 h}$ & $\mathbf{2 4 h}$ \\
\hline Dilation of Bowman's space & - & + & - & ++ & - \\
Increase in diameter of renal tubules & - & + & - & - & - \\
Hyperemia & - & - & + & ++ & ++ \\
Shrinkage of glomerulus & - & - & + & - & - \\
Congestion of glomerulus & - & - & - & + & ++ \\
Tubular necrosis & - & - & - & + & ++ \\
\hline
\end{tabular}

Note none: $(-)$, mild: $(+)$, moderate: $(++)$ and severe: $(+++)$

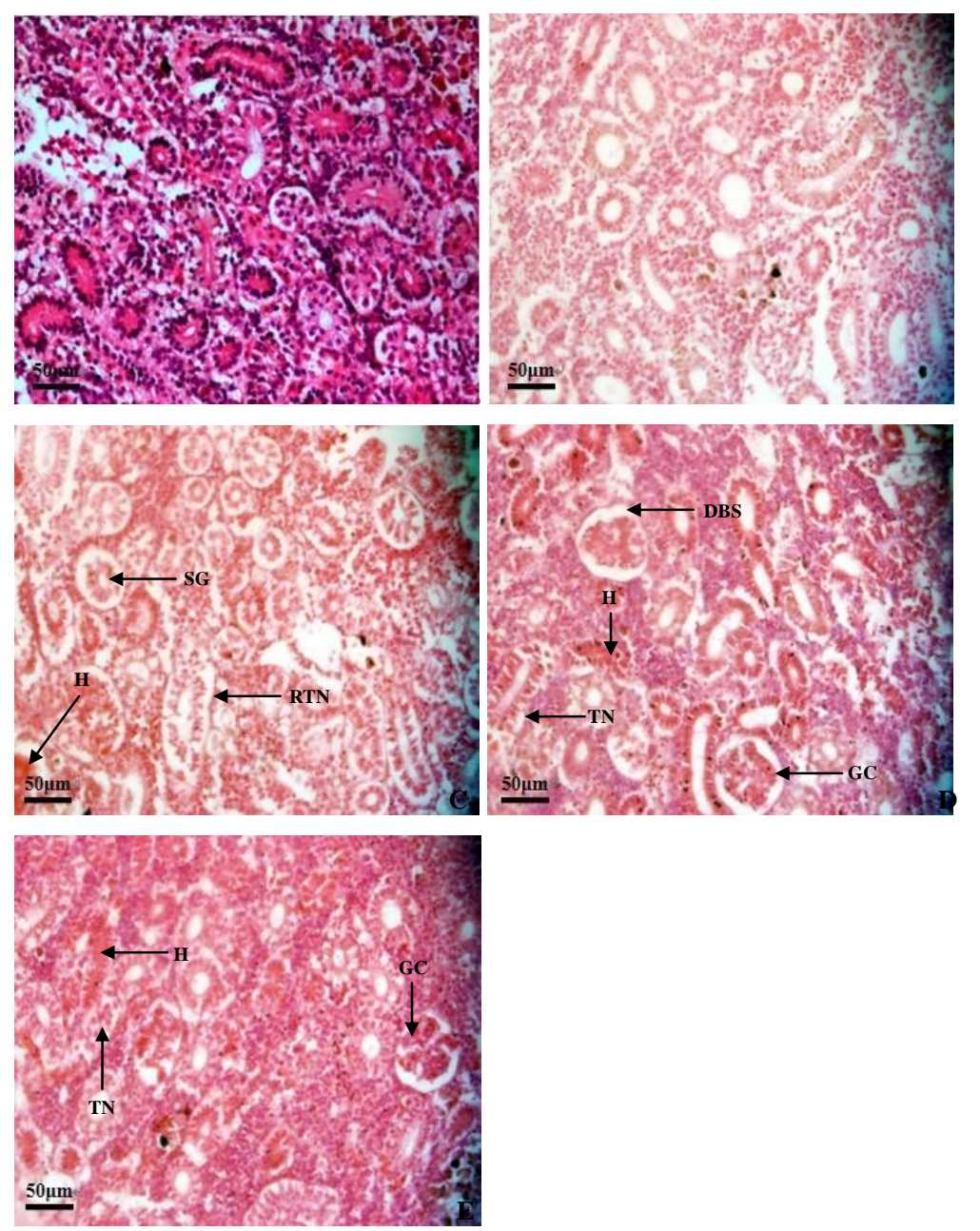

Fig. 3 (A-E) Histopathological evaluation of Aristichthys nobilis kidney exposed to acute high-temperature stress. (A) Kidney structure of control fish at $28^{\circ} \mathrm{C}$. (B) Kidney after $3 \mathrm{hr}$ at $38^{\circ} \mathrm{C}$. (C) Kidney after $6 \mathrm{hr}$ at $38^{\circ} \mathrm{C}$. (D) Kidney after $12 \mathrm{hr}$ at $38^{\circ} \mathrm{C}$. (E) Kidney after $24 \mathrm{hr}$ at $38^{\circ} \mathrm{C}$. Glomerulus, (G); renal tubules, (RT); increased diameter of renal tubules, (IRT); dilation of Bowman's space, (DBS); shrinkage of glomerulus, (SG); renal tubules necrosis, (RTN); hyperemia, (H); tubular necrosis, (TN); glomerular congestion, (GC). All sections stained with $\mathrm{H} \& \mathrm{E}$ and visualized at $400 \times$ magnification. Scale bar (50) $\mu \mathrm{m}$. 


\section{Histopathological changes in tissues of bighead carp following acute \\ high-temperature}

\section{Discussion}

The use of histopathological markers has been proposed as an efficient and sensitive tool for monitoring fish health and environmental pollution (Camargo \& Martinez, 2007). Gills are more sensitive to pollutants because of their large surface area and external location (Olurin et al., 2006; Camargo \& Martinez, 2007). In this study, fish exposed to acute high-temperature stress displayed severe histological alterations compared to the control, namely, epithelial lifting and edema, blood congestion, thickening of the primary lamellae epithelium, and curling, fusion, and shortening of the secondary lamellae.

Lifting of lamellar epithelial cells from the basement membrane due to high-temperature stress was the first lesion observed in this study. This could reduce overall respiratory gas exchange as a result of increased diffusion distance and smaller inter-lamellar distance. It has been suggested that lifting of the lamellar epithelium is induced by severe edema (Olurin et al., 2006). Others have hypothesized that this epithelial lifting might be beneficial, increasing the distance across which waterborne pollutants must diffuse to reach the bloodstream (Alexopoulos et al., 2003).

We also observed the appearance of blood vessels in the secondary lamellae. Since stress can cause changes in blood vessels, it is possible that this histopathological alteration resulted from the collapse of the pillar cell system and breakdown of vascular integrity. This would release a large quantity of blood pushing the lamellar epithelium outwards. We observed increased thickness of epithelial layers, including mucous cell hyperplasia and fusion of adjacent secondary lamellae, which would likely decrease the surface area available for oxygen extraction. It would also increase the oxygen diffusion distance between water and blood (Kayode et al., 2016). Therefore, the fusion and thickening of the primary lamellae epithelium likely decreases the efficiency of respiration and osmoregulation in heat-shocked fish. We also observed shortening and curling of secondary lamellae. Similar observations were reported in Chanos chanos after acute endosulfan toxicity (Kumar et al., 2016) and Channa punctatus (Bloch) exposed to hexavalent chromium (Mishra \& Mohanty, 2008).

On the other hand, the teleost liver is a detoxification organ essential for metabolism and excretion of toxic substances (Camargo \& Martinez, 2007). Histology of the fish liver could serve as a useful model for studying interactions between the environment and hepatic structures. In the present study, we found that acute high-temperature stress clearly induced liver karyolysis, necrosis, and hyperemia, dilation in sinusoids, nuclear hypertrophy, and congestion of the central vein.

Severe alterations were observed in liver anatomy after fish were exposed to heat shock, resulting in necrosis. The results of this study are consistent with previous findings which showed that when the liver is damaged, blood flow blocks the sinusoids, causing blood to backflow from the hepatic portal vein and hepatic artery into the central vein. This causes the observed congestion of the central vein (Olurin et al., 2006). Hypertrophy, which is an increase in cellular size, is generally caused by exposure to compounds that induce proliferation of the endoplasmic reticulum (Hadi \& Alwan, 2012). In perch, venous hyperemia from a metal-contaminated lake was found to cause similar disturbances in hepatic blood circulation. This affected major and minor blood vessels, as well as hepatic sinusoids, and was most likely due to common vein congestion (Yancheva et al., 2015). Sinusoid dilation and blood congestion in white sea-bass as a result of acute and sub-chronic cadmium exposure was also observed (Thophon et al., 2003).

The kidneys of fish receive the majority of post-branchial blood, and renal lesions are considered good indicators of environmental stress (Ortiz et al., 2003; Cengiz, 2006). In the present study, acute high-temperature stress caused fish to display obvious histological alterations such as dilation of the Bowman's space, an increase in the diameter of renal tubules, hyperemia, tubular necrosis, and shrinkage and congestion of glomeruli.

Shrinkage of the glomeruli and an increase in voids within the Bowman's capsule were also observed after exposure to lindane (Ortiz et al., 2003). Necrosis of the tubular epithelium, hypertrophied epithelial cells in the renal tubules, narrowing of 
the tubular lumen, expansion of the space inside the Bowman's capsules, and contraction of the glomeruli in Cirrhinus mrigala exposed to fenvalerate have also been observed (Velmurugan et al., 2007). Similar results have been reported in olive flounder infected by scuticociliatosis caused by Philasterides discentrarchi (Harikrishnan et al, 2010). However, there are no reports in the literature which describe the effects of acute high-temperature stress on kidney tissue in fish. Our results are the first to demonstrate extensive kidney damage following heat shock.

This study demonstrates the utility of histopathology for assessing environmental stress and toxic exposure in fish. Although we studied only one species, our findings corroborate toxicity studies previously performed with other fish. Our thorough histological examination of the internal organs (gills, liver, and kidneys) confirms that these fish are extremely vulnerable to fluctuations in the temperature of their environment. This information will encourage aquaculturists to carefully monitor culture temperature to minimize stress to the animals.

\section{Acknowledgements}

This work was financially supported by the National "Twelfth Five-Year" Plan for Science \& Technology Support [grant number 2012BAD25B07], the Natural Science Foundation of Jiangsu province, China [grant number BK20151103], the Modern Agriculture Industrial Technology System Special Project-the National Technology System for Conventional Freshwater Fish Industries [grant number CARS-46], and the Chinese Academy of Fishery Sciences, the China Central Governmental Research Institutional Basic Special Research Project from Public Welfare Fund [grant number 2015C06XK01].

\section{References}

Alexopoulos E., McCrohan C.R., Powell J.J., Jugdaohsingh R. and White K.N., 2003. Bioavailability and toxicity of freshly neutralized aluminium to the freshwater crayfish Pacifastacus leniusculus. Arch Environ Contam Toxicol., 4(4): 509-514.

Camargo M.M., and Martinez C.B., 2007. Histopathology of gills, kidney and liver of a Neotropical fish caged in an urban stream. Neotrop Ichthyol., 5, 327 - 336.

Cengiz E.I., 2006. Gill and kidney histopathology in the freshwater fish Cyprinus carpio after acute exposure to deltamethrin. Environ Toxicol Pharmacol. 22(2): 200-204.

Cremer M.C., Smitherman R.O., 1980. Food habits and growth of silver and bighead carp in cages and ponds. Aquaculture 20, 57-64.

FAO Fish stat., 2014. Global Aquaculture production for species (tonnes). FAO Fisheries and Aquaculture Department accessed November 2016. www.fao.org

FAO., 2004. National aquaculture legislation overview- China. In: Spreij, M. (Ed.), National Aquaculture Legislation Overview (NALO) Fact Sheets. FAO Fisheries and Aquaculture Department, Rome, Italy

(http://www.fao.org/fishery/legalframework/nalo_china/ en\#tcNB0041).

Fisk A.T., Hobson K.A., Norstrom R.J., 2001: Influence of chemical and biological factors on trophic transfer of persistent organic pollutants in the North water Polynya marine food web. Environ Sci Technol., 35: 732-738.

Hadi A.A., Alwan S.F., 2012. Histopathological changes in gills, liver and kidney of fresh water fish, Tilapia zillii, exposed to aluminium. Int J Pharm \& Life Sci., (IJPLS), 3(1102071-2081.

ISSG., 2005. Ecology of Aristichthys nobilis. Global Invasive Species Database. 8 July 2005.

http://www.issg.org/database/species/ecology.asp?si=773\&fr=1\&sts=sss. Last accessed: 2 May 2006.

Kayode B.O., Godwin O.M., Olubunmi A.A., 2016. Histopathological effect of sub-lethal concentration of aluminum phosphide (phostoxin) on Clarias gariepinus juveniles. Pesq Vet Bras., 36(7):574-580. 
Kumar N., Ambasankar K., Krishnani K.K., Gupta S.K., Bhushan S., Minhas P.S., 2016. Acute toxicity, biochemical and histopathological responses of endosulfan in Chanos chanos. Ecotoxicology and Environmental Safety 131, 79-88. Lee S., Ji K., Choi K., 2014. Effects of water temperature on perchlorate toxicity to the thyroid and reproductive system of Oryzias latipes. Ecotoxical. Environ Saf., 108, 311-317.

Marina M.P., Camargo and Cláudia B.R., Martine., 2007. Histopathology of gills, kidney and liver of a Neotropical fish caged in an urban stream. Neotrop Ichthyol., 5(3):327-336.

Mishra A. K., Mohanty B., 2008. Acute toxicity impacts of hexavalent chromium on behavior and histopathology of gill, kidney and liver of the freshwater fish, Channa punctatus (Bloch). Environ Toxicol Pharmacol., 26, 136-141.

Olurin K., Olojo E.A.A., Mbaka G.O. and Akindele A.T., 2006. Histopathological response of the gills and liver tissues of Clarias gariepinus to herbicidie glyphosat. African J Biotechnol., 5(24), 2480-2487.

Opuszynski K., 1981. Comparison of the usefulness of the silver carp and the bighead carp as additional fish in carp ponds. Aquaculture 25, 223-233.

Ortiz J.B., Gonzalez de Canales M.L. and Sarasquete C., 2003. Histopathological changes induced by lindane $(Y-H C H)$ in various organs of fish. Sci. Mar. 67: 53-61.

Paithane K.T., Sonawane D.L., Bhandare R.Y., More P.R., 2012: Histophatological changes due to induced dimethoate in the liver of freshwater fish Channa punctatus from river Shivana, Aurangabad (M.S) India. The Ecoscan Special Issue 1: 213-217.

Ramasamy Harikrishnan., Chang-Nam Jin., Man-Chul Kim., Ju-Sang Kim., Chellam Balasundaram., Moon-Soo Heo., 2010. Histopathology and Mortality in Olive Flounder Infected by Scuticociliatosis caused by Philasterides discentrarchi. Isr. J. Aquacult.-Bamidgeh, 62(3), 2010, 202-211.

Thophon S., Kruatrachue M., Upathan E.S., Pokethitiyook P., Sahaphong S., Jarikhuan S., 2003. Histopathological alterations of white seabass, Lates calcariferin acute and subchronic cadmium exposure. Environ Pollut., 121: 307-320.

USGS., 2005. Bighead Carp. Florida Integrated Science Centre. 20 December 2005. http://fisc.er.usgs.gov/Carp_ID/html/hypophthalmichthys_nobilis.htmlLast accessed: 2 May 2006.

Velmurugan B., Selvanayagam M., Cengiz E., Unlu E., 2007. The effects of fenvalerate on different tissues of freshwater fish Cirrhinus mrigala. J Environ Sci Health $B ; 42: 157-63$.

Yancheva V., Velcheva I., Stoyanova S., Georgieva E., 2015. Histological biomarkers in fish as a tool in ecological risk assessment and monitoring programme: A review. Appl Ecol Environ Res., 14 (1): 47-75. 